\title{
Quantitative modelling of granular suspension flows
}

\author{
By Herbert E. Huppert \\ Institute of Theoretical Geophysics, Department of Applied \\ Mathematics and Theoretical Physics, University of Cambridge, \\ Silver Street, Cambridge CB3 9EW, UK
}

\begin{abstract}
A broad review is presented of the flow of particulate suspensions. The fundamental concepts are discussed and the governing equations described. Simplified horizontally uniform box-model solutions are obtained and numerical integrations of the nonlinear shallow-water equations are presented, along with a brief description of an approach using the full power of the techniques of computational fluid dynamics. Extra situations, such as the influence of a mean external flow, interstitial fluid which is less dense than the ambient, plumes, entrainment of the ambient, and polydispersivity, are reviewed. Applications from engineering and the Earth sciences are described.
\end{abstract}

Keywords: shallow-water equations; particulate suspension flows; box-model solutions; external mean flows; light interstitial fluid; buoyant plumes

\section{Introduction}

The synopsis for this Meeting asks the following questions. Can materials which consist of individual particles be treated as continuous materials when they flow and are transported by air or water and subsequently deposited? Can a single model capture all behaviours? This paper aims to address these questions in a quantitative fashion in order to analyse situations when a relatively low concentration of small, heavy particles is advected along by, and at the same time sediments from, a largescale turbulent flow.

Vigorous particle-driven flows occur in a large variety of natural and industrial situations. In the oceans, turbidity currents which consist of large volumes of sand and silt can propagate many hundreds of kilometres across the ocean floor (Heezen \& Ewing 1952; Middleton 1993; Dade \& Huppert 1994) with the largest one yet uncovered representing a deposit of $500 \mathrm{~km}^{3}$ (Rothwell et al. 1998; see also the accompanying news and views article (Nisbet \& Piper 1998)). They can occur as a consequence of severe storms over shallow coastal waters, catastrophic failures of the continental slope or surges in muddy river run-off in times of heavy rains. In the atmosphere, severe dust storms can be generated by the picking up of loose particles from the ground. Following an explosive volcanic eruption, a turbulent plume of hot, ash-laden particles can quickly be taken up into the stratosphere (Woods 1995), influencing the weather, and even the climate. Alternatively, if the contribution of the ash particles to the bulk density of the plume is sufficiently large, a ground-hugging pyroclastic flow is generated, which can propagate at speeds of up to hundreds of metres per second (Dade \& Huppert 1995). In the industrial context, the particle-laden output of pollution into the atmosphere or a neighbouring body of water is a common 
occurrence. A determination of the concentration of the pollutant as a function of space and time is of great importance from both a scientific and a legal point of view (Hunt 1991; Hunt et al. 1991).

This paper reviews some of the recent work on the propagation of large-scale particle-laden flows. Section 2 concentrates on the fundamentals involved in a quantitative description of gravity currents, which occur whenever fluid of one density flows predominantly horizontally into fluid of a different density. Part of the aim of any investigation in this area is to predict the rate of propagation of the flow and the resulting sedimentation profile. Sections 3-5 present a discussion of the various models and associated mathematical techniques used to obtain solutions. The subsequent sections discuss a variety of extra effects, such as the imposition of a mean flow, the influence of the density of the interstitial fluid being different from that of the ambient, an intrusion resulting from a rising plume, the effects of entrainment of ambient fluid and polydispersivity of the particulate matter. Where possible, the results are compared with laboratory experiments. Applications of the results to real large-scale situations are also briefly described.

\section{Fundamental concepts}

The propagation of fluid of one density predominantly horizontally into fluid of a different density is described as a gravity current. The fundamental nature of gravity currents has been extensively documented by Simpson (1997) and many of their intriguing properties are the subject of intense investigation at the moment. The propagation of a gravity current at large Reynolds number, for which viscous effects are unimportant and whereby the current propagates under a balance of inertial and buoyancy forces, was first analysed by von Kármán (1940) in a famous essay. With the use of the Bernoulli equation in a manner that was made rigorous by Benjamin (1968) in a subsequent study, von Kármán showed that when a gravity current intrudes along a rigid horizontal plane beneath a very deep, otherwise motionless, fluid, the velocity of the front of the current $u_{N}$ is related to the depth of the current just behind the head $h_{N}$ by

$$
u_{N}=\operatorname{Fr}\left(g^{\prime} h_{N}\right)^{1 / 2}
$$

where the reduced gravity

$$
g^{\prime}=\left(\rho_{\mathrm{c}}-\rho_{\mathrm{a}}\right) g / \rho_{\mathrm{a}}
$$

is defined in terms of the gravitational acceleration $g$ and the densities $\rho_{\mathrm{c}}$ and $\rho_{\mathrm{a}}$ of the current and ambient, respectively, and $F r$ is the (constant) Froude number associated with the flow. According to perfect fluid theory and the incorporation of the Boussinesq approximation, $\mathrm{Fr}=\sqrt{ } 2$, but experimental investigations by Huppert \& Simpson (1980) established a value of 1.19 when a real current is propagating as the result of the instantaneous release of a fixed volume of fluid. The difference between the two values accounts for the viscous drag and turbulent Reynolds stresses which are present in any real flow and act to slow down the propagation of the current. If the current is the result of an instantaneous release of heavy fluid into a shallow layer of depth $H$, with $H<h_{N} / 0.075$, motions in the upper layer influence the flow and the appropriate Froude number is given by $0.5\left(h_{N} / H\right)^{-1 / 3}$. All studies have used (2.1) as an effective boundary condition at the front of the current.

Phil. Trans. R. Soc. Lond. A (1998) 
When the gravity current is driven by excess buoyancy arising from the presence of suspended heavy particles, the driving buoyancy force continually changes with time and position because the heavy particles settle out of the flow as well as being advected along with it. The approach most frequently taken to analyse the sedimentation is to assume that the (high Reynolds number) flow is sufficiently turbulent to maintain a vertically uniform particle concentration in the main body of the current. But at the base of the flow, where the fluid velocities diminish appreciably, the settling of particles occurs (at low Reynolds number) at the Stokes velocity $V$ in otherwise quiescent fluid. Quantitatively, this implies that if $N$ (which is possibly a function of time and position) denotes the total number of particles per unit horizontal area in a layer of depth $h$, the change in $N, \delta N$, in time $\delta t$ due only to the sedimentation is given by

$$
\delta N=-V C_{0} \delta t,
$$

where $C_{0}$ is the (number) concentration (per unit volume) just above the base of the flow. Since the vigorous turbulent mixing implies that $C_{0}=N / h,(2.3)$ indicates (on taking the appropriate infinitesimal limits) that

$$
\dot{N}=-V N / h,
$$

a relationship which has been carefully verified by Martin \& Nokes $(1988,1989)$, though the theoretical result had been suggested earlier and independently by others (Einstein 1968; McCave 1970; Pantin 1979). Equation (2.4) does not yet incorporate the advection of the particles by the mean flow, which, when done, results in the more familiar form

$$
\frac{\mathrm{D} \phi}{\mathrm{D} t}=-\frac{V \phi}{h},
$$

where $\phi$ is the volume concentration of particles.

The above, turbulent, model for the advection and sedimentation of particles has been used extensively. An alternative, laminar, model has been recently suggested and its consequences investigated by Ungarish \& Huppert (1998). They supposed that the particles sediment at a uniform velocity throughout the flow. The upper interface of the current was then defined by the kinematic shock which follows the top of the sedimenting layers of particles. In this model, particle-free interstitial fluid of the current is detrained through the upper interface. For typical values of the input flow parameters there were only small differences between the two sets of results.

The relationships (2.1) and (2.5) (or the simplified version (2.4)) are the basis of many of the analytical investigations of particle-driven gravity currents.

\section{Box models}

The simplest analysis for the propagation speed of and deposition from a particledriven gravity current proceeds by constructing a simple box model of the flow which assumes that at any particular time there is no horizontal variation of properties within the flow. In this approach, the current is considered to evolve in a series of rectangles of equal area (neglecting entrainment, which will be discussed in $\S 9$ ). The major advantage of this approach is that it leads to the correct dimensional form of solution which, in addition, can be expressed analytically in closed form.

Phil. Trans. R. Soc. Lond. A (1998) 
As an illustrative example, consider the two-dimensional instantaneous release of a fixed cross-sectional area $A$ of particle-laden fluid with initial volume concentration of particles $\phi_{0}$ (Hallworth et al. 1998). The density of the current $\rho_{\mathrm{c}}$ is then related to the volume concentration $\phi$ by

$$
\rho_{\mathrm{c}}=\rho_{\mathrm{p}} \phi+\rho_{\mathrm{a}}(1-\phi),
$$

where $\rho_{\mathrm{p}}$ is the density of the particles and $\rho_{\mathrm{i}}$ the density of the interstitial fluid, has been assumed equal to that of the ambient $\rho_{\mathrm{a}}$. (Different values of $\rho_{\mathrm{i}}$ and $\rho_{\mathrm{a}}$ are considered in $\S 7$.) The reduced gravity (2.2) is then linearly related to $\phi$ by

$$
g^{\prime}=g_{\mathrm{p}}^{\prime} \phi
$$

where

$$
g_{\mathrm{p}}^{\prime}=\left(\rho_{\mathrm{p}}-\rho_{\mathrm{a}}\right) g / \rho_{\mathrm{a}} .
$$

With the length of the current denoted by $l(t)$, the box model reduces to determining the solution of

$$
\begin{aligned}
h l & =A, \\
i & =F r\left(g_{\mathrm{p}}^{\prime} \phi h\right)^{1 / 2}, \\
\dot{\phi} & =-V \phi / h,
\end{aligned}
$$

subject to

$$
\begin{gathered}
l=0, \\
\phi=\phi_{0},
\end{gathered}
$$

at $t=0$.

Dividing $(3.4 c)$ by $(3.4 b)$, using $(3.4 a)$ to eliminate $h$ and solving the resulting first-order equation subject to (3.5), we obtain the result

$$
\phi / \phi_{0} \equiv \Phi=\left(1-\xi^{5 / 2}\right)^{2}
$$

in terms of the non-dimensional variable $\xi \equiv l / l_{\infty}$, where $l_{\infty}=\left(25 \mathrm{Fr}^{2} g_{\mathrm{p}}^{\prime} \phi_{0} A^{3} / V^{2}\right)^{1 / 5}$ is the final length of the current, at which point $\phi=0$. The variation of $\xi$ with time is obtained by substituting (3.4a) and (3.6) into (3.4b) and using the initial condition (3.5 a) to obtain

$$
\tau \equiv \operatorname{Fr}\left(g_{\mathrm{p}}^{\prime} \phi_{0} A\right)^{1 / 2} l_{\infty}^{-3 / 2} t=\int_{0}^{\xi} \frac{s^{1 / 2} \mathrm{~d} s}{1-s^{5 / 2}} \equiv \mathcal{F}(\xi) .
$$

With a Froude number of 1.19, these relationships are plotted, along with some data presented previously (Bonnecaze et al. 1993; Dade \& Huppert 1994), in figure 1a. In preparing this figure, all observed lengths were divided by 1.6 because while the box model correctly predicts the functional form of the various relationships, it overestimates the value of $l_{\infty}$ by a factor of $c a .1 .6$ (as explained in more detail in Bonnecaze et al. 1995; Hallworth et al. 1998; Hogg et al. 1999a). The proposed scaling collapses all the data well to provide generally good agreement between the box-model results and the experimental data. It has been argued that the differences are probably due to slow return motions in the upper layer of the experiments (Bonnecaze et al. 1993; Hallworth et al. 1998), which are completely neglected in the box model.

Phil. Trans. R. Soc. Lond. A (1998) 
(a)
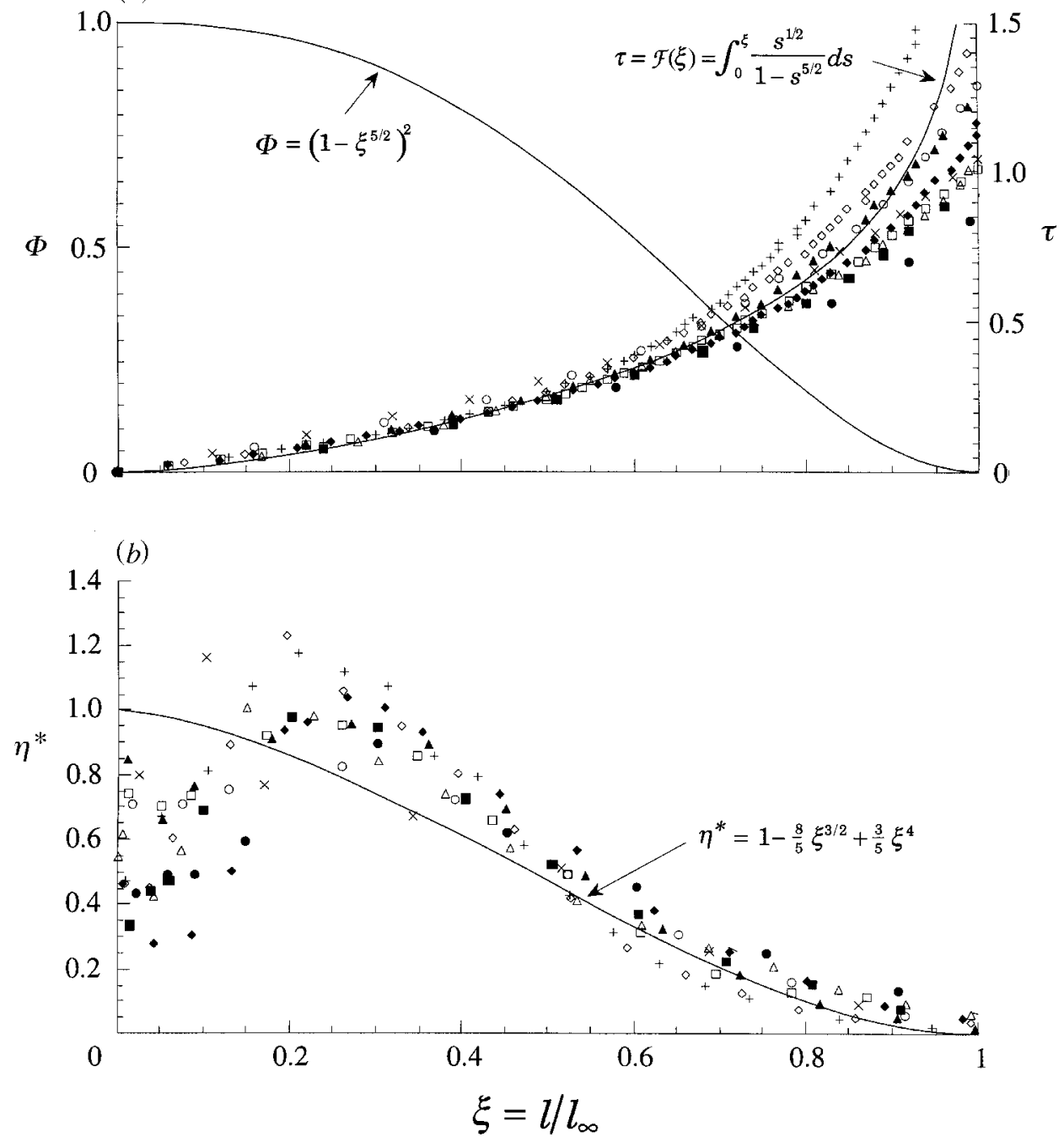

Figure 1. Experimental data and box-model solutions for a fixed volume of a particulate suspension released instantaneously from behind a lock gate. The data are from laboratory experiments presented in Bonnecaze et al. (1993) and Dade \& Huppert (1994) covering a large range of initial conditions. (a) The non-dimensional volume fraction $\Phi$ (equation (3.6)) and time $\tau$ (equation (3.7)) as functions of the non-dimensional current length $\xi$. (b) The non-dimensional deposit density $\eta^{*}$ (where $\eta^{*}=12 l_{\infty} \eta /\left(25 \phi_{0} \rho_{\mathrm{P}} A\right)$ from equation (3.9)) plotted as a function of $\xi$.

The resulting deposit distribution can be evaluated from the statement that in time $\delta t$, a mass per unit width $\delta M=-\rho_{\mathrm{P}} A \delta \phi$ is distributed uniformly over a length $l$ to lead to a deposit density

$$
\delta \eta=-\rho_{\mathrm{P}} A \delta \phi / l
$$

Phil. Trans. R. Soc. Lond. A (1998) 
The final total deposit density is thus given by

$$
\eta=-\rho_{\mathrm{p}} A \int_{0}^{l_{\infty}} s^{-1} \frac{\mathrm{d} \phi}{\mathrm{d} s} \mathrm{~d} s=\frac{25 \rho_{\mathrm{P}} \phi_{0} A}{12 l_{\infty}}\left(1-\frac{8}{5} \xi^{3 / 2}+\frac{3}{5} \xi^{4}\right),
$$

which is graphically illustrated and compared with experimental data in figure $1 b$. The experimental data is again in good agreement with the theoretical results, except near the back of the channel where the particles seem to be swept downstream more than the theory would suggest.

There exist many other box-model solutions, all of which give a good indication of the form of the full solution and can be easily and quickly derived. Examples include axisymmetric currents (Dade \& Huppert 1995; Huppert \& Dade 1998), currents generated by a fixed flux (Dade \& Huppert 1995, 1996; Hallworth et al. 1999), currents propagating in a mean flow $(\S 2 d$; Hallworth et al. 1998, 1999), currents with an interstitial density which is less than the ambient even though the bulk density is, at least initially, larger than the ambient (Sparks et al. 1993; Hogg et al. 1999b), and currents influenced by rotation (Ungarish \& Huppert 1998, 1999). Recently, Hogg et al. (1999a) have shown how, by taking horizontal integrals of the full shallow-water equations, the errors in the box-model approach can be rigorously determined.

\section{Shallow-water equations}

A more accurate representation of the flow can be obtained by using shallow-water theory (Whitham 1974) which allows for horizontal variations of properties in the flow, but still assumes that there are no vertical variations because the intensity of the flow is sufficient to keep the current well mixed (in the vertical). Vertical accelerations in the flow are neglected and the pressure distribution is assumed to be hydrostatic. The validity of this approach is based on the requirement that the horizontal extent of the current greatly exceeds its (vertical) thickness. For a one-dimensional current, on the assumption that the ambient is sufficiently deep compared to the thickness of the current that motions within the ambient can be neglected, the single-layer shallow-water equations describing conservation of mass and momentum are

$$
h_{t}+(u h)_{x}=0
$$

and

$$
(u h)_{t}+\left(u^{2} h+\frac{1}{2} g^{\prime} h^{2}\right)_{x}=0,
$$

while the conservation of particles is given by (2.5). Suitable boundary conditions are given by zero flow at the end wall $x=0$, which indicates that

$$
u(0, t)=0,
$$

and the Froude number condition (2.1) at the other end of the current. A compositional current, for which the density difference is due to a dissolved salt, for example, can be analysed formally by considering $V \equiv 0$ and $\phi$ constant, $\phi_{0}$, say. There then exists a similarity solution to the equations which results in the relationship

$$
l(t)=\left(\frac{27 F r^{2}}{12-2 F r^{2}}\right)^{1 / 3}\left(g^{\prime} A\right)^{1 / 3} t^{2 / 3} .
$$

Phil. Trans. R. Soc. Lond. A (1998) 
The box-model approach leads to the same form, as it must, except that the premultiplicative factor is replaced by $\left(\frac{3}{2} F r\right)^{2 / 3}$.

The validity of this long-time solution, which is appropriate only after the initial slumping phase during which fluid adjusts from its initial configuration, has been extensively confirmed (Huppert \& Simpson 1980).

For a particulate gravity current, with non-zero $V$, a similarity solution does not exist and recourse must, in general, be made to numerical solutions. However, for small values of $V$, explicitly for small values of the non-dimensional settling number $\beta=V /\left(g_{0}^{\prime} h_{0}\right)^{1 / 2}$, where $g_{0}=g_{\mathrm{p}}^{\prime} \phi_{0}$ and $h_{0}$ are the initial values of the reduced gravitational acceleration and thickness of the current, respectively, Hogg et al. (1999a) have recently devised a perturbation expansion, in similarity variables, about the similarity solution valid for $\beta \equiv 0$. Further, Harris (1998) has shown how to render the expansion uniformly valid for all time.

Evaluating the numerical solution of the governing equations, Bonnecaze et al. (1993) found that experimental results agreed better with numerical solutions of the two-layer equations and these were almost as easy to obtain. In this case, the equations of conservation of mass in the two layers are

$$
h_{t}+(u h)_{x}=0
$$

and

$$
\hat{h}_{t}+(\hat{u} \hat{h})_{x}=0,
$$

where a hat indicates a variable in the ambient layer. A momentum balance for the two layers can then be written as

$$
(u h)_{t}+(H-h)\left(u^{2} h+\frac{1}{2} g_{\mathrm{p}}^{\prime} \phi h^{2}\right)_{x}+h[u h(H-h)]_{x}=0 .
$$

The two-layer model is made up of (2.5), $(4.5 a)$ and (4.6) for the three variables that describe the gravity current, $h, v$ and $\phi$, together with the appropriate boundary conditions (2.1) and (4.3). Note that there are no adjustable parameters associated with the equations.

The numerical integration of the equations is relatively easy to code, with the details described by Bonnecaze et al. (1993), and recent extensions set out by Hogg et al. (1999a). The numerical solutions indicate that two types of shocks, represented as travelling bores, can occur in the current. The first only occurs if the initial height of the current is comparable with (greater than $c a .70 \%$ of) the depth of the ambient. This bore develops in the initial or slumping phase of the current (Huppert \& Simpson 1980; Rottman \& Simpson 1983). With the removal of the lock separating the dense fluid from the relatively less dense ambient, a heavy gravity current begins to develop while, simultaneously, another gravity current of ambient fluid travels over and against the relatively dense underflow in the form of a lock-exchange flow until it reaches the end wall. A bore is then reflected towards the front which it eventually overtakes and then disappears (figure 2). This marks the beginning of the validity of the similarity form of solution for a compositional current; but the bore is quite similar and just as important in a particulate current. The bore is completely absent in a box model (or a similarity solution), but the numerical solution of the shallow-water equations indicates that it has a significant influence on the pattern of sediment deposition (as indicated quantitatively in figs 13 and 14 of Bonnecaze et al. (1993)).

Phil. Trans. R. Soc. Lond. A (1998) 


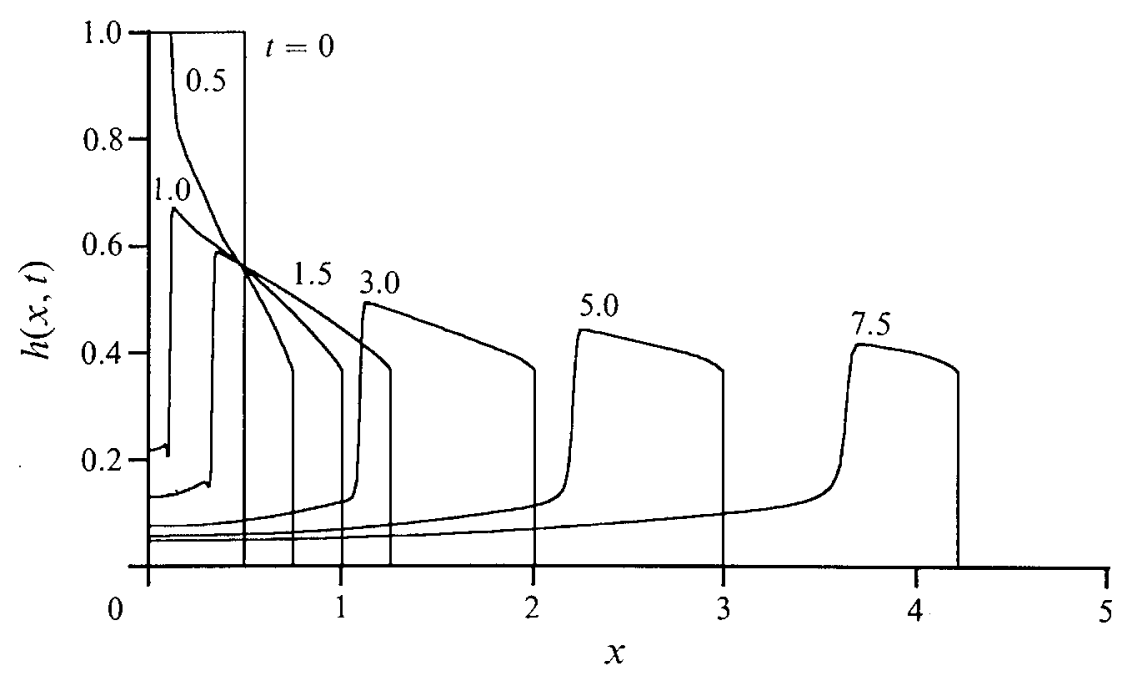

Figure 2. The numerically determined profiles of the height $h(x, t)$ at various non-dimensional times, as marked, of a collapsing heavy suspension intruding into a shallow ambient fluid. Taken from fig. $3 b$ of Bonnecaze et al. (1993).

The second shock, in the form of a travelling internal bore, develops in the late stages of all particle-driven currents and separates a particle-free jet-like flow in the rear from a relatively densely laden particulate flow near the front. After the first bore (or wave in a deep ambient) has waned, the current shape approaches the self-similar form associated with a compositional current: during this stage few particles settle and the current behaves like a compositionally driven current. As the current proceeds and the particles begin to settle, they do so more rapidly towards the rear of the current where the height is less (cf. equation (2.4)), reducing the density and pressure gradient in the tail of the current. With time, the particle concentration in the tail approaches zero and the motion in the tail is a consequence of the remaining momentum in the relatively particle-free fluid (and the effects of buoyancy are negligible). Near to the front, however, buoyancy forces still play a dominant role and a travelling bore is a result of the matching of the jet-like flow in the rear to the buoyancy-driven flow at the front.

The agreement between the numerical solutions of the two-layer shallow-water equations and the results of laboratory experiments in a $10 \mathrm{~m}$ long channel using different initial masses of fairly monodisperse silicon carbide particles (density $3.217 \mathrm{~g} \mathrm{~cm}^{-3}$ ) suspended in water are excellent. Figure $3 a$ presents the numerical and experimental results for the length of the current as a function of time for a series of different initial mass loadings, while figure $3 b$ presents the density of deposit as a function of length down the channel.

An axisymmetric extension of the above study has been reported by Bonnecaze et al. (1995). They considered currents created either by the instantaneous release of a finite volume of fluid or by a constant flux. The numerical solutions of the axisymmetric shallow-water equations agreed fairly well with the results of their numerous laboratory experiments. In particular, they determined that the final radial extent, $r_{\infty}$, of a particle-driven current resulting from the instantaneous release of a 

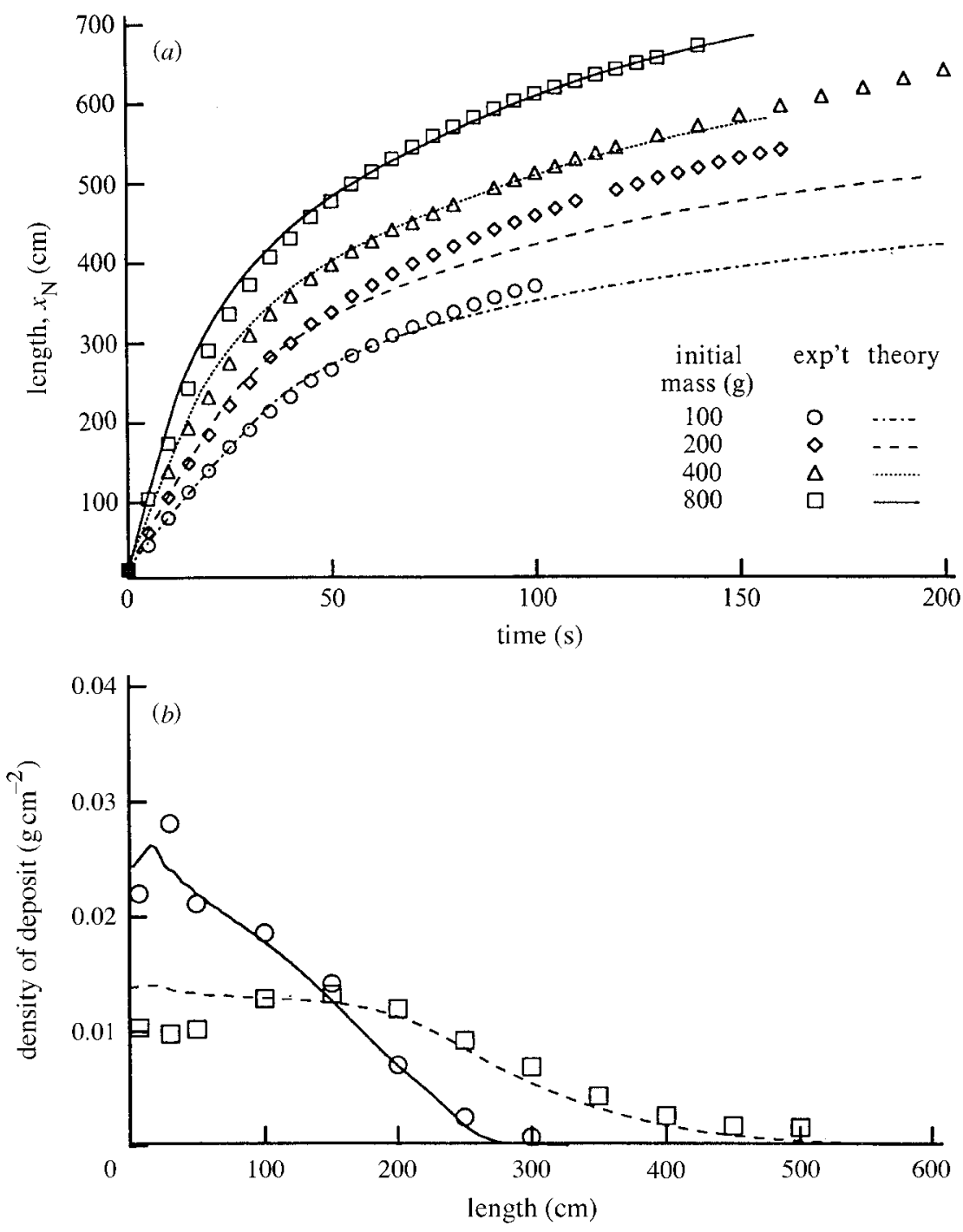

Figure 3. (a) The length as a function of time for a $1.2 l$ suspension with different initial masses of nominally $37 \mu \mathrm{m}$ diameter silicon carbide particles released instantaneously into a channel of water $26 \mathrm{~cm}$ wide by $30 \mathrm{~cm}$ deep. The symbols are the experimental measurements and the curves are numerical results obtained by integration of the two-layer shallow-water equations. Taken from figure $12 b$ of Bonnecaze et al. (1993). (b) The final areal density of deposit as a function of downstream length for an initial mass of $100 \mathrm{~g}$ of nominally $23 \mu \mathrm{m}$ ( $\square-$ - - -) and $53 \mu \mathrm{m}(\mathrm{o}-)$ diameter particles. All other parameters are as described for $(a)$. Taken from fig. 13 of Bonnecaze et al. (1993).

volume $Q$ of fluid is given by

$$
r_{\infty}=1.9\left(g_{0}^{\prime} Q^{3} / V^{2}\right)^{1 / 8} .
$$

An axisymmetric box model leads to (4.7) with a constant of 1.1 replacing the 1.9 (Dade \& Huppert 1995; Huppert \& Dade 1998).

Phil. Trans. R. Soc. Lond. A (1998) 

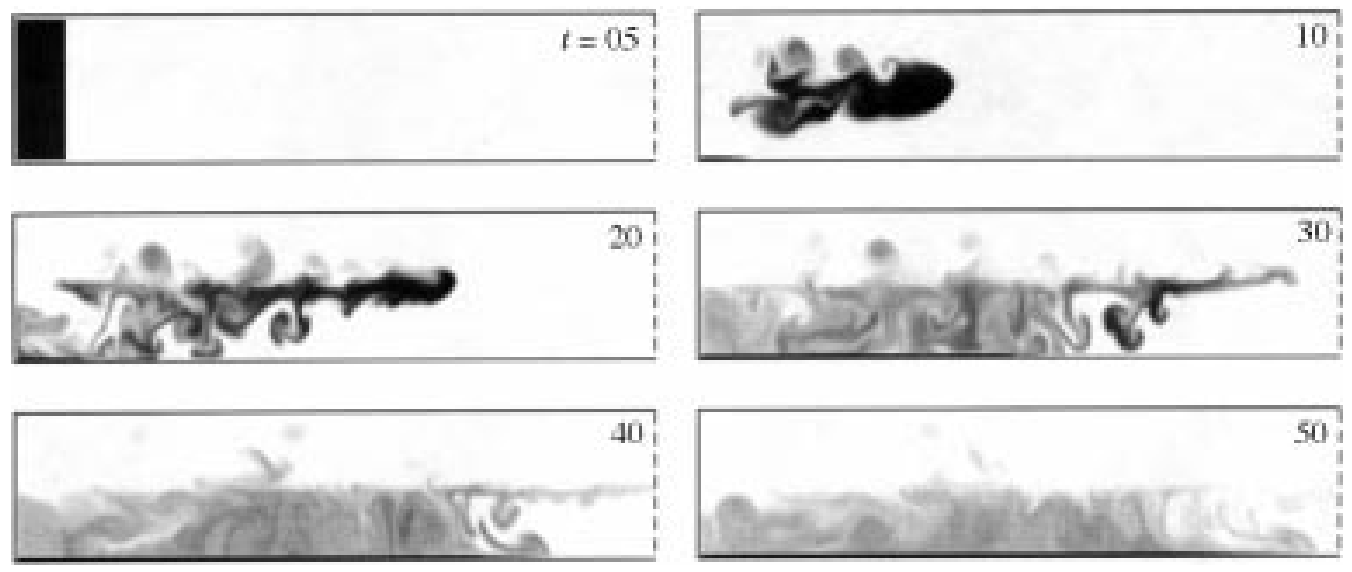

Figure 4. The grey scale level representing particle concentration for a particulate intrusion of initial bulk density $1.01 \mathrm{~g} \mathrm{~cm}^{-3}$ between a lower layer of density $1.18 \mathrm{~g} \mathrm{~cm}^{-3}$ underneath an upper layer of density $1.00 \mathrm{~g} \mathrm{~cm}^{-3}$.

\section{Further numerical codes}

Numerous full-scale CFD codes have been written to follow particle-driven flows. Many of these are tailored to investigate particular flows. The models generally include a large number of adjustable parameters, which is rather unsatisfactory. The CFD investigation into these problems best known to me, which has no adjustable parameters, is currently being undertaken by S. Dalziel and associates of the Department of Applied Mathematics and Theoretical Physics, University of Cambridge. The code SETTLE (Dalziel \& Linden 1997) is based on the two-dimensional streamfunction-vorticity equations for an inviscid Boussinesq fluid. The implementation allows for the advection of multiple scalar quantities, each contributing to the local bulk density. Suspended particles are treated in a continuum manner identical to the treatment of solutes, but with an additional advection term to model the settling of the particles. Some modification of the boundary conditions is also required to allow particles to 'stick' to the lower boundary and prevent resuspension. Polydisperse suspensions may be modelled by including multiple scalar fields with different densities and fall velocities. The numerical solution employs a finite-volume discretization on a staggered grid with a third-order monotonic advection scheme for all advected scalars.

Dalziel has adapted the numerical code to consider the two-dimensional intrusion of an instantaneous release of a fixed volume of suspension into a compositionally stratified ambient represented either by a two-layer system or by a continuous stratification. Figure 4 presents the results of one simulation. Particles gradually sediment from the current, which runs out of its driving buoyancy after ca. $40 \mathrm{~s}$. The numerical results are in good agreement with experimental data (de Rooij et al. 1999) and the calculated final sedimentation density as a function of distance somewhat surprisingly agrees well with the results obtained by Bonnecaze et al. (1993) using the shallow-water equations described in the last section to calculate the deposit from a heavy suspension intruding at the bottom of a fresh-water layer (figure 5). It is too early to document fully the advantages of using such CFD packages on the problems 


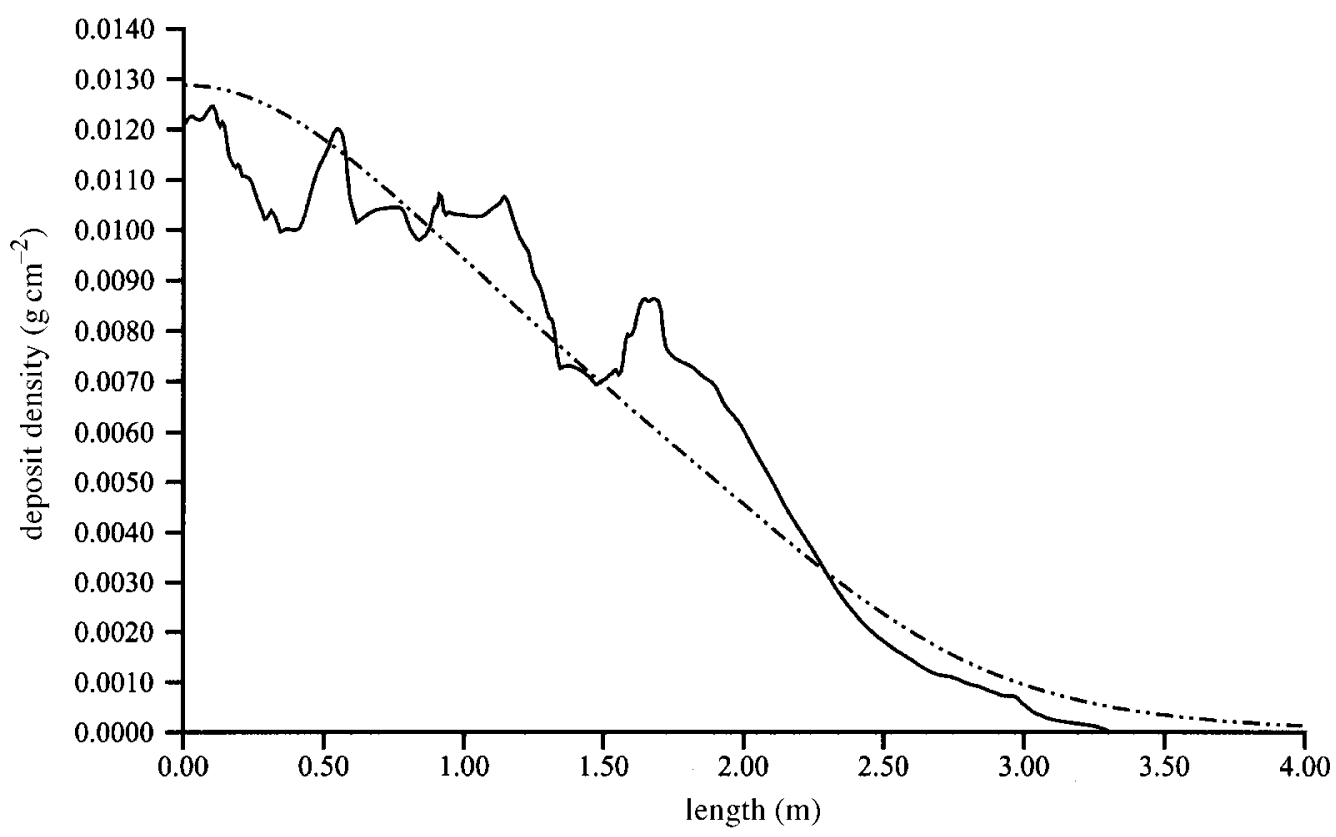

Figure 5. The final areal density of deposit as a function of downstream length determined by: use of the numerical code SETTLE with the same conditions as for figure 4 (solid line); and the results of using the two-layer nonlinear shallow-water equations of Bonnecaze et al. (1993) for $40 \mathrm{~g}$ of particulate matter with $\beta=0.0205$ released from a lock $20 \mathrm{~cm}$ long by $20 \mathrm{~cm}$ wide by $10 \mathrm{~cm}$ deep (dash-dot line).

of interest to us here, or to know the fluid-dynamical phenomena which they can (accurately) predict, in contrast to the shallow-water simulations.

\section{The influence of an external mean flow}

The motivation of von Kármán's original study published in 1940, in response to a request from the American military before World War II, was to determine the minimum wind speed which would blow a gravity current of released nerve gas back onto friendly troops. Although that explicit question was not answered by von Kármán, some analyses of the effects of mean winds in the atmosphere on the propagation of a compositional gravity current have been undertaken (Simpson \& Britter 1980; Xu 1992; Xu \& Moncrieff 1994). Recently, Hallworth et al. (1998) considered the influence of a uniform mean flow in the ambient on the upstream and downstream propagation in a two-dimensional geometry of a particle-driven (or compositional) gravity current due to the instantaneous release of a fixed volume per unit width of fluid $A$ at the base of the flow.

A simple box model of the flow, based on the working hypothesis that at all times the particle flow distribution in the current and its height are uniform in the horizontal direction, is represented by the following (cf. equation (3.4)). The conservation of volume condition,

$$
l \equiv x+y=A / h,
$$

Phil. Trans. R. Soc. Lond. A (1998) 
the two front conditions,

$$
\begin{aligned}
& \dot{x}-U=F r\left(g_{\mathrm{p}}^{\prime} \phi h\right)^{1 / 2}, \\
& \dot{y}+U=F r\left(g_{\mathrm{p}}^{\prime} \phi h\right)^{1 / 2},
\end{aligned}
$$

and the conservation of the particles' constraint,

$$
\dot{\phi}=-V \phi / h
$$

where $x$ and $y$ are the downstream and upstream length of the current, respectively, and $U$ is the effective mean external flow as experienced by the current. With the initial conditions (3.5), the system (6.1)-(6.3) can be easily shown to have solutions (Hallworth et al. 1998)

$$
\begin{aligned}
& \Phi=\left(1-L^{5 / 2}\right)^{2}, \\
& T=\mathcal{F}(L)
\end{aligned}
$$

and

$$
\mathcal{Z}=\Lambda T
$$

where the non-dimensional variables

$$
\begin{aligned}
& L=l / l_{\mathrm{p}}, \\
& \mathcal{Z}=(x-y) / l_{\mathrm{p}}
\end{aligned}
$$

and

$$
T=t / \tau_{\mathrm{p}}
$$

have been defined in terms of the length- and time-scales,

$$
\begin{aligned}
l_{\mathrm{p}} & =2^{2 / 5} l_{\infty}, \\
\tau_{\mathrm{p}} & =5 A /\left(l_{\mathrm{p}} V\right)
\end{aligned}
$$

and the single non-dimensional parameter,

$$
\Lambda=10 U A /\left(l_{\mathrm{p}}^{2} V\right)
$$

which is proportional to the ratio of the mean external velocity to the settling velocity of the particles. Note that the current ceases $(\phi=0)$ when $l=l_{\mathrm{p}}$ independent of the ambient flow speed or $\Lambda$.

Comparing the theoretical results $(6.4 b),(6.4 c)$ with numerous experiments carried out in a long channel through which was pumped a fairly uniform mean flow, $\bar{U}$, at the rate of $2.9 \mathrm{~cm} \mathrm{~s}^{-1}$, Hallworth et al. (1998) found that the nondimensionalization suggested by the box model collapsed the data extremely well and indicated that $U=0.62 \bar{U}$, in good agreement with earlier experiments on a much smaller scale by Simpson \& Britter (1980).

They also calculated the deposit distribution profiles, which became more asymmetric with increasing $\Lambda$. The agreement between these theoretical calculations and their experimental data was very good and the asymmetry predicted by the theory was accurately reflected in the data. The maximum upstream distance that the current can penetrate, $l_{+}$, can also be easily calculated, and Hallworth et al. (1998) derived the approximate representation

$$
\frac{l_{+}}{l_{\mathrm{p}}}=\frac{\frac{1}{2}+\left(\frac{1}{5} \log \Lambda-\frac{1}{8} \pi\right)+\frac{1}{50} \Lambda^{2}}{1+\frac{3}{25} \Lambda^{4}},
$$




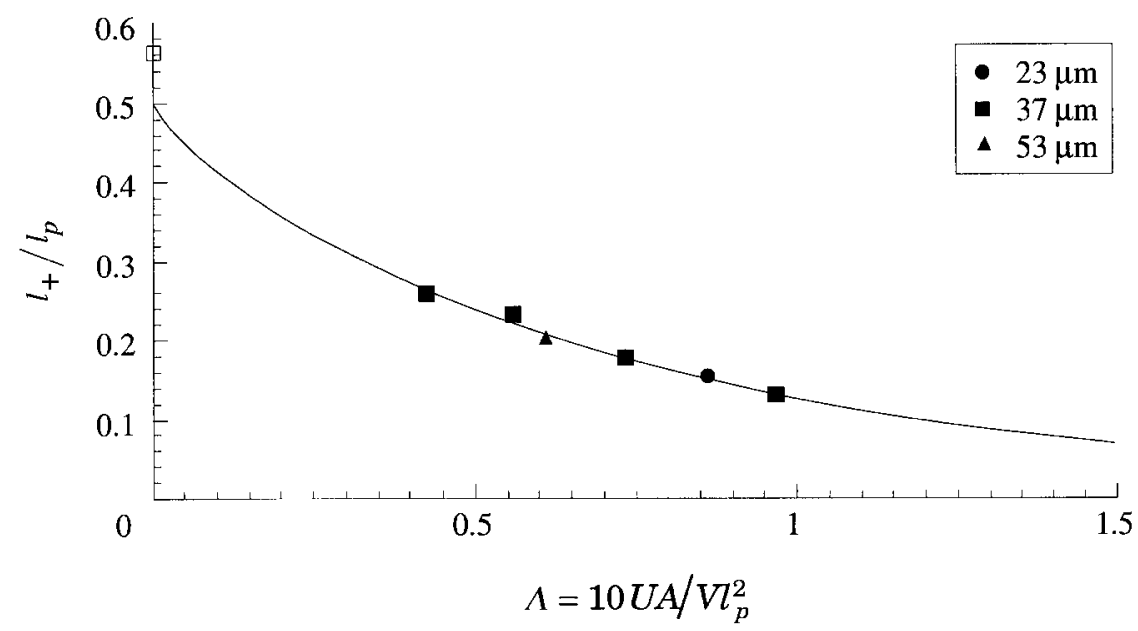

Figure 6. The maximum non-dimensional upstream distance of a particulate intrusion in a uniformly flowing ambient, $l_{+} / l_{\mathrm{p}}$, as a function of $\Lambda=10 U A /\left(V l_{\mathrm{p}}^{2}\right)$.

which is presented, in excellent agreement with their experimental data, in figure 6 . They also obtained numerical solutions of the single- and two-layer shallow-water equations which compared well with the results from the box model.

The extension of these results to cover the release of a constant flux (rather than a fixed volume) is currently being considered by Hallworth et al. (1999). In addition, the influence of an external flow on the release of particle-rich fluid from a point source, which analyses the interaction between a two-dimensional current and an axisymmetric release, has been investigated by Hogg \& Huppert (1999). Using a box model in a reference frame translating with the current, they determine the geometrical shape and extent of the current as a function of time and the distribution of the deposit within that region, the area of which increases monotonically with time.

\section{Less dense interstitial fluid}

There are many natural occurrences of sediment-laden gravity currents in which the density of the interstitial fluid is less than that of the ambient, which in itself is less than the bulk density of the current. Such currents are driven by the excess density of suspended particles. However, after sufficient particles have sedimented, the current will become buoyant, cease its lateral motion and ascend to form a plume.

With these concepts in mind, Carey et al. (1988) conducted a series of qualitative experiments in which heavy sediment-laden fresh-water currents spread radially from a point source along the floor of a tank containing salty water. After some time, the forward motion of the flow front ceased and an axisymmetric ring of vigorous plumes was generated. The behaviour of a layer of suspended fine particles in fresh water placed below a layer of salt water, with the bulk density of the suspension larger than that of the upper layer, which was larger than that of the interstitial fluid, was quantitatively investigated by Huppert et al. (1991) and Kerr \& Lister (1992). As sedimentation in the otherwise stagnant lower layer progressed, buoyant fluid was released across the interface between the two layers, resulting in convection and mixing of the finer fractions of the sediment throughout the upper layer. Huppert et al.

Phil. Trans. R. Soc. Lond. A (1998) 
presented a theoretical model which predicts the evolution of the lower layer and the amount of particle entrainment into the upper layer, with results in good agreement with their laboratory experiments. The constraining effects of a concentration gradient in the upper layer, a situation relevant to numerous oceanographic situations, was evaluated by Kerr (1991), who applied his results directly to data taken in the Sulu Sea (Quadfasel et al. 1990).

These works partly motivated an experimental and theoretical study of sedimentladen gravity currents with buoyant interstitial fluid (Sparks et al. 1993). A theoretical model, incorporating the shallow-water approach outlined in $\S 4$, led to numerical predictions for the rate of propagation, the distance at which lofting takes place and the distribution of the final deposit, all of which were in good agreement with the experimental observations.

A box-model approach, following the concepts outlined in $\S 3$, commences by writing

$$
\rho_{\mathrm{c}}=\rho_{\mathrm{p}} \phi+\rho_{\mathrm{i}}(1-\phi),
$$

where $\rho_{\mathrm{i}}$, the density of the interstitial fluid, is less than $\rho_{\mathrm{a}}$. The reduced gravity

$$
g^{\prime}=c_{\mathrm{p}} \phi-c_{\mathrm{a}},
$$

where

$$
\begin{aligned}
& c_{\mathrm{p}}=\left(\rho_{\mathrm{p}}-\rho_{\mathrm{i}}\right) g / \rho_{\mathrm{a}} \\
& c_{\mathrm{a}}=\left(\rho_{\mathrm{a}}-\rho_{\mathrm{i}}\right) g / \rho_{\mathrm{a}} .
\end{aligned}
$$

We then seek the solution of $(3.4 a),(3.4 c)$ subject to (3.5) in conjunction with

$$
i=\operatorname{Fr}\left[\left(c_{\mathrm{p}} \phi-c_{\mathrm{a}}\right) h\right]^{1 / 2} .
$$

After some fairly straightforward manipulations, we find that the position of lift-off, $l_{*}$, is given by

$$
\left(l_{*} / l_{\infty}\right)=[\mathcal{G}(\gamma)]^{2 / 5}
$$

where, as derived in $\S 3, l_{\infty}=\left(25 F r^{2} g_{\mathrm{p}}^{\prime} \phi_{0} A^{3} / V^{2}\right)^{1 / 5}, \gamma=\left(\rho_{\mathrm{a}}-\rho_{\mathrm{i}}\right) /\left[\left(\rho_{\mathrm{p}}-\rho_{\mathrm{i}}\right) \phi_{0}\right]$ and

$$
\mathcal{G}(\gamma)=(1-\gamma)^{1 / 2}-\gamma^{1 / 2} \tan ^{-1}\left(\gamma^{-1}-1\right) \text {. }
$$

(If the current propagates in shallow water $(h>0.075 H)$, the relationship $(7.5)$ is replaced by

$$
l_{*} / l_{\infty}=[\mathcal{G}(\gamma)]^{6 / 13} .
$$

For an axisymmetric flow in a very deep ambient, the lift-off radius $r_{*}$ is given by

$$
\left(r_{*} / r_{\infty}\right)=[\mathcal{G}(\gamma)]^{1 / 4}
$$

(Dade \& Huppert 1995), where $r_{\infty}=\left(64 F r^{2} g_{\mathrm{p}}^{\prime} \phi_{0} Q^{3} / \pi^{3} V^{2}\right)^{1 / 8}$ and $Q$ is the released volume of the flow.)

Figure 7 presents a series of datum points from three different experimental situations along with graphs of $[\mathcal{G}(\gamma)]^{2 / 5}$ and $[\mathcal{G}(\gamma)]^{6 / 13}$. The agreement between the data and both curves is seen to be fairly good, with a slightly closer agreement to the model for a shallow ambient, the situation in which most of the data were taken. A more complete discussion of this work is currently being prepared for publication (Hogg et al. 1999b).

Phil. Trans. R. Soc. Lond. A (1998) 


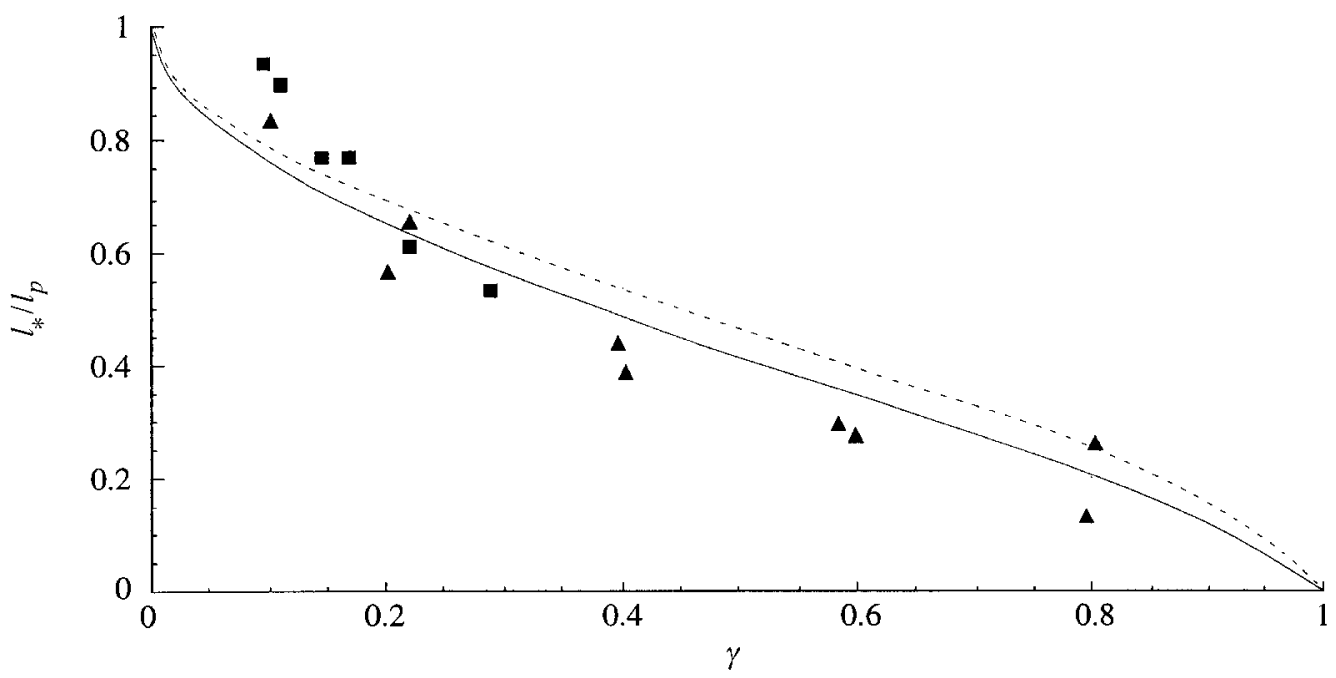

Figure 7. The non-dimensional distance to lift-off $l_{*} / l_{\mathrm{p}}$ as a function of the non-dimensional parameter $\gamma$ for a suspension of heavy particulate matter in an interstitial fluid which is less dense than the ambient. The data points are from experiments with the density difference between the interstitial and ambient fluid arising from alcohol being added to the interstitial fluid $(\boldsymbol{\Delta})$ or salt being added to the ambient $(\boldsymbol{\bullet})$. The dashed curve represents $\left(l_{*} / l_{\mathrm{p}}\right)=[\mathcal{G}(\gamma)]^{2 / 5}$, which is the result of a box-model analysis for a very deep ambient, and the solid curve represents $\left(l_{*} / l_{\mathrm{p}}\right)=[\mathcal{G}(\gamma)]^{6 / 13}$, which is the result of a box-model analysis for a shallow ambient.

The above processes are believed to play an important role in the generation of ash-rich co-ignimbrite plumes from pyroclastic flows. Sedimentation in the initially ground-hugging pyroclastic flow and the heating of the entrained cold air by the small ash particles causes a mixture of hot air and fine suspended particles to become buoyant relative to the overlying atmosphere. A spectacular example of such a process occurred to the blast flow resulting from the eruption of Mt St Helens in 1980, which penetrated some $30 \mathrm{~km}$ into the atmosphere after travelling between 15 and $20 \mathrm{~km}$ along the ground at velocities of around $100 \mathrm{~m} \mathrm{~s}^{-1}$ (Sparks et al. 1997). Similar co-ignimbrite clouds occurred as the result of the eruption of Mt Pinatubo in 1991 and are believed to have been associated with many previous large pyroclastic flow eruptions.

Analogous lift-off phenomena can occur from turbidity currents transporting sediment suspended in relatively light water from the continental shelf and shallow-water coastal regions into deep parts of the ocean basin, where the density of the (salty) water is relatively larger. The relatively fresh coastal water can thereby be mixed into deeper water a considerable distance off-shore. The same phenomena will influence the sedimentation patterns at delta fronts and estuaries when sediment-laden fresh or brackish water intrudes into the sea water.

\section{Plumes}

The motion of a turbulent buoyant plume above a continuous constant source was investigated by Morton et al. (1956), who introduced the famous entrainment hypothesis (Turner 1986). Using a combination of dimensional analysis and laboratory experimentation, they considered a pure buoyant plume of specific buoyancy

Phil. Trans. R. Soc. Lond. A (1998) 
flux $F$ rising in a stably stratified environment of constant buoyancy frequency $N$. As the plume rises, entrains and mixes in relatively dense air from the environment, the density in the plume increases with height, in contrast to the density of the ambient, which decreases. The plume reaches a height at which the net buoyancy is zero; it overshoots somewhat, then settles back slightly and spreads horizontally into the environment as an axisymmetric gravity current of constant flux. The height, $H$, of the centre of this current above the source is given by

$$
H=3.8 F^{1 / 4} N^{-3 / 4},
$$

a relationship which, derived from a laboratory experiment in which $H \approx 0.1 \mathrm{~m}$, was shown to be valid for a large oil fire for which $H$ was in excess of $3000 \mathrm{~m}$ (Briggs 1969). These ideas were incorporated into various models for volcanic eruption columns, as summarized in Sparks et al. (1997), to yield good agreement with observed heights of rise $H \sim 4 \times 10^{4} \mathrm{~m}-$ a successful extrapolation from the original laboratory scale of over five orders of magnitude.

A volcanic plume contains many small (heavy) ash particles: those still remaining as the plume intrudes laterally into the atmosphere will be advected along with it, while at the same time some will settle out of the gravity current and deposit on the ground (and a fraction may be entrained back into the plume). The laboratory simulations of Carey et al. (1988) were conducted to simulate this behaviour. Buoyant plumes of sediment-laden fresh water were generated at the base of a layer of fresh water, rose to the top of the layer and then spread as gravity currents along the upper surface. The experimental data were then described quantitatively (Sparks et al. 1991) by adapting (2.4) in the following way. In the steady axisymmetric flow with radial velocity $u_{r}$ of a layer of turbulent fluid of thickness $h$, the rate of change of the mass, $M$, of suspended particles in the current with radial distance $r$ will be given, following (2.4), by

$$
\frac{\mathrm{d} M}{\mathrm{~d} r}=\frac{-V M}{u_{r} h} .
$$

Because the flow is steady, $Q=2 \pi r h u_{r}$ is constant and so (8.2) has the solution

$$
M=M_{0} \exp \left[-\pi V\left(r^{2}-r_{0}^{2}\right) / Q\right],
$$

where $M_{0}$ is the mass of particles in the current at radius $r_{0}$. Figure $8 a$ presents the experimental data and the relationship (8.3) for five different particle sizes with a separate $V$ associated with each particle. The agreement is surprisingly good. This comparison was then followed up by Bursik et al. (1992), who compared the sedimentation density of tephra of the Fogo A plinean deposit on the island of San Miguel in the Azores from the umbrella cloud associated with the eruption of the Agua de Pau Volcano about 3000 BCE. The results of their investigation are presented in figure $8 b$, again showing good agreement between theory and observations for different particle sizes.

Further details of particle sedimentation from volcanic clouds, including effects due to fall out from, and re-entrainment by, the volcanic column and the influence on the sediment distribution of a mean wind are reviewed in Sparks et al. (1997). This work also contains a chapter on the exciting area of hydrothermal plumes, which issue at temperatures of $c a .350{ }^{\circ} \mathrm{C}$ through vents at the bottom of the ocean. The particles in these plumes, consisting mainly of fine-grained sulphides, are formed in situ by 

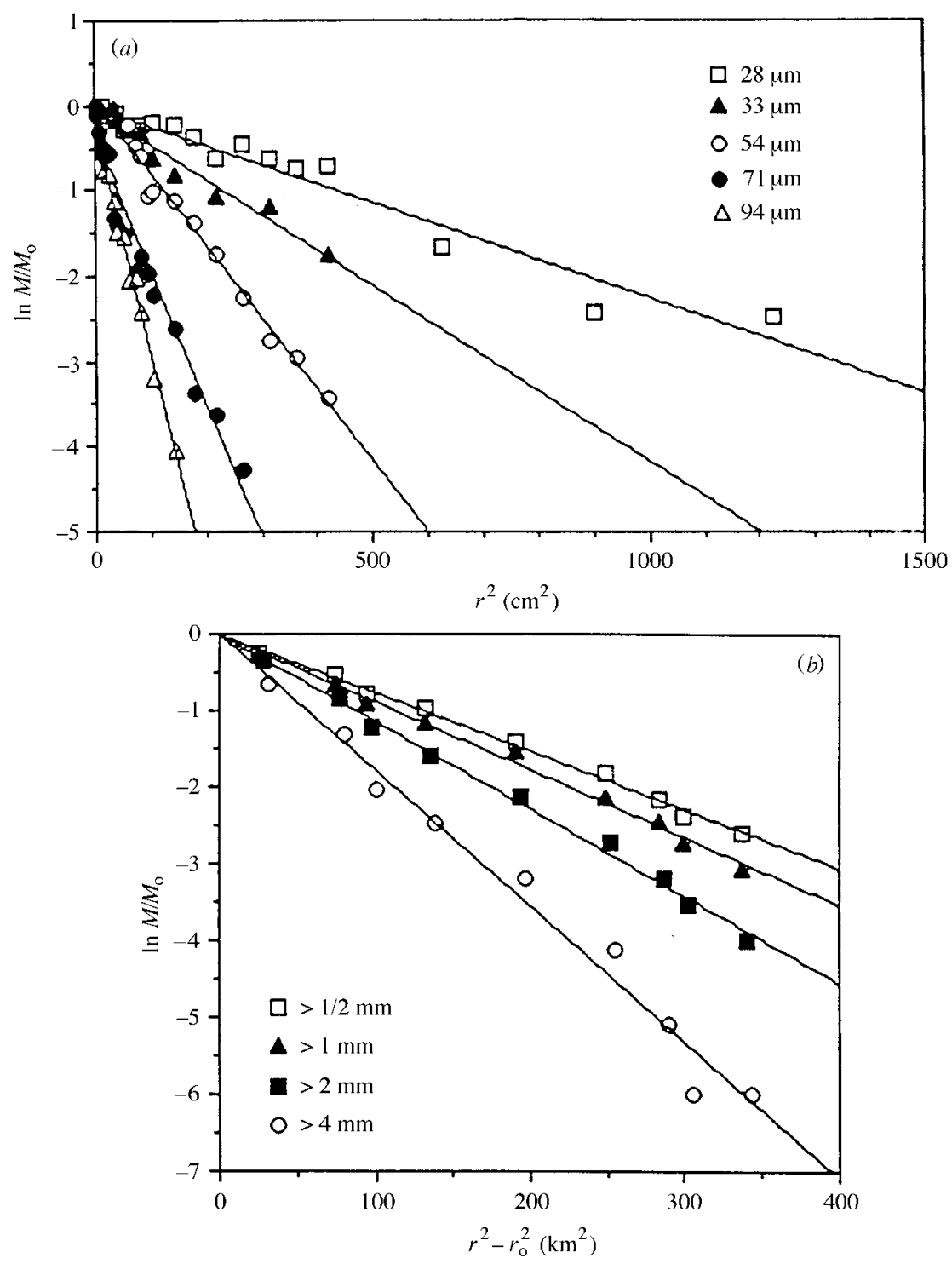

Figure 8. The mass of sedimentation (on a log scale) as a function of the square of the radius for different particle sizes, (a) from laboratory measurements (Sparks et al. 1991) and (b) from the Fogo A deposit (Bursik et al. 1992). The straight lines represent the theoretical relationship $(8.3)$.

chemical reactions which are initiated by the entrainment of ambient sea water. It has been estimated that more than $50 \%$ of the particles that sediment from the rising plume can be re-entrained into it at lower levels.

\section{The effects of entrainment}

In the discussion so far, the fluids that make up the current and the ambient have been considered distinct: effects of entrainment have been neglected, and the total volume 
of the gravity current remains constant as it propagates. This has been well known to be false for quite some time. As the heavy fluid of the current propagates into the relatively less dense environment, for example, it traps some ambient fluid beneath it, which rises into the head of the current and (unless the fluids are immiscible) mixes with it. How large is this entrainment (which is completely different from the entrainment across the whole bounding surface of a turbulent plume, as introduced by Morton et al. (1956)), and how is it reflected in the rate of propagation of the current?

To answer these questions, Hallworth et al. $(1993,1996)$ carried out a series of particle-free experiments using a novel neutralization technique, in order to quantify the entrainment. A known amount of a basic salt $(\mathrm{NaOH})$ and some $\mathrm{pH}$ indicator was mixed into the original fluid which made up the gravity current and which intruded into and entrained an acidified ambient. The current propagated with a deep blue (basic) head which, at a measurable distance (and time), quite suddenly turned red, indicating that the predetermined amount of dilution had taken place in the head of the current. Guided by these experimental results, Hallworth et al. constructed a theoretical model which predicts quantitatively the entrainment into the head of a current as a function of distance from the source. For the instantaneous release of a constant volume of fluid in a two-dimensional geometry, for example, they showed, by using dimensional analysis, that a dimensionless entrainment or dilution ratio $E$, defined as the ratio of the volumes of ambient and original fluid in the head, is independent of the initial reduced gravity of the current, as confirmed by their experiments. The model indicated further that entrainment into the head is negligible $(E \approx 0)$ in the slumping phase, during which the current is adjusting into an almost self-similar form. Beyond that it is well represented by

$$
E=\left[1+\frac{1}{2} \frac{(\alpha-k) y}{A_{\mathrm{s}}^{1 / 2}}\right]^{2 \alpha /(\alpha-k)}-1,
$$

where $y$ is the distance of propagation since the end of the slumping phase, at which point the area of the head is $A_{\mathrm{s}}$, and $\alpha$ and $k$ are experimentally determined constants which reflect the amount of entrainment into the head and the ratio of the height of the tail to that of the head, respectively. Hallworth et al. (1996) determined the values of $\alpha$ and $k$ for flow over a smooth $(\alpha=0.073, k=0.16)$ or rough $(0.080,0.20)$ rigid base or under a free surface $(0.016,0.18)$ (and $(0.081,0.16)$ for axisymmetric currents propagating over a smooth base). They also extended the model to predict that, taking into account the effects of entrainment, the propagation distance as a function of time should obey

$$
Y=1-\left[1-\frac{k-3 \alpha}{2(k-\alpha)} T\right]^{2(k-\alpha) /(k-3 \alpha)},
$$

where $Y$ and $T$ are suitably non-dimensionalized distance and time, respectively. This relationship may not look like the two-thirds similarity form of (4.4). However, with the experimentally determined values of $\alpha$ and $k$, it does not depart much from the two-thirds form; this explains why predictions based on the similarity solution (4.4), obtained without recourse to the effects of entrainment, are in good agreement with data obtained from real entraining gravity currents.

Phil. Trans. R. Soc. Lond. A (1998) 


\section{Polydispersion}

Most of the research described so far has assumed that the particles are of one size, and can hence be represented by one value of the settling velocity, $V$. However, in practice, there is a range of particle sizes: in the experimental laboratory the variation may be as little as $\pm 20 \%$ about the mean, but in real geological situations there may be a variation in size by as much as five orders of magnitude.

As described in $\S 8$, Sparks et al. (1991) handled this variation in interpreting their data in the simplest possible way: they associated each particle size independently with its own free-fall speed. And this yielded encouraging results. However, it suggested that each particle size is advected independently of all the other particles in the current, a conclusion which is clearly incorrect. A box-model investigation of two particle sizes with different initial concentrations was presented by Dade \& Huppert (1995). They concluded that, for the same initial density difference, the influence of the smaller, less easily deposited, particles was to extend and hence thin the current more rapidly. This leads to an earlier, more rapid, deposition of the larger particles. At the same time, however, the larger particles are transported to greater distances. While these conclusions are (probably) correct, the quantitative distinction between the two particle sizes seems to be overestimated by this box-model approach - and strongly so as the ratio of the sizes of the two particles increases (Gladstone et al. 1998).

A more rigorous approach uses the nonlinear shallow-water equations described in $\S 4$. Using dimensional analysis on these equations, Bonnecaze et al. (1996) developed a scaling of the single-layer equations so that all the parameters appeared only in the initial conditions. The long-time solution of these 'master' equations was obtained, which were independent of all details of the initial conditions except for the total volume. Bonnecaze et al. then proposed that the total deposit could be obtained from a direct superposition of the deposit from individual-sized particles. Quantitatively, they argued that for the instantaneous release into a deep layer of fluid of a fixed (two-dimensional) volume of $A$ of a suspension of $N$ particle sizes, each with Stokes's free-fall speed $V_{i}$ and initial volume concentration $\phi_{i 0}(i=1,2, \ldots, N)$, the total deposit density $\eta(x)$ could be written in terms of a shape function $W(s)$ as

$$
\eta(x)=\rho_{\mathrm{P}} A \sum_{i=1}^{N} \phi_{i 0} \sigma_{i} W\left(\sigma_{i} x\right),
$$

where

$$
\sigma_{i}=\left[\frac{V_{i}^{2}}{g_{0}^{\prime} A^{3}}\right]^{1 / 5}
$$

and

$$
g_{0}^{\prime}=g_{\mathrm{p}}^{\prime} \sum_{i=1}^{N} \phi_{i 0},
$$

with an accurate representation of $W(s)$ being given by

$$
W(s)=\frac{0.820}{1+0.683 s^{2}+0.017 s^{8}} .
$$

Phil. Trans. R. Soc. Lond. A (1998) 
This theoretical representation was in good agreement with the results of a series of laboratory experiments using five different particle sizes. The paper also presents quantitative results for an axisymmetric release.

A nicely conceived, well-ordered series of laboratory experiments in which dilute suspensions made of two particle sizes were released into relatively shallow water has recently been conducted by Gladstone et al. (1998). They confirmed, qualitatively, the earlier conclusions of Dade \& Huppert (1995) and Bonnecaze et al. (1996), but there was quantitative agreement with the results of Bonnecaze et al. only during the late stages of each experiment when the current had thinned sufficiently for the influence of motions in the upper layer to be negligible (as assumed in the theory).

It is my opinion that there is still more to be determined quantitatively in this matter. In particular, no (numerical) calculation (known to me) has investigated the all-important determination of the distribution of size in the deposit with height, which is the quantity measured by, and of most interest to, geologists.

\section{Applications from engineering and the Earth sciences}

This section will briefly describe applications of some of the analyses presented so far to real large-scale situations in engineering and the Earth sciences. The description will (I hope for understandable reasons) concentrate on situations I have been strongly involved in myself, though these represent but a small proportion of the problems to which the ideas are relevant.

\section{(a) Dredging of harbours}

The Ministry of Agriculture, Fisheries and Food recently approached me about a novel dredging technique being employed in British harbours and waterways by a Dutch company. A broad jet of water was rapidly discharged from a long $(c a .20 \mathrm{~m})$ pipe held horizontally a few centimetres above a bed of loose sand and silt. Some of the bedload was lifted into the water column, in a way described quantitatively by Hogg et al. (1997). The resultant suspension was to propagate out to sea, aided by the tidal flow. This is the situation described by the analysis presented in $\S 6$ and in Hallworth et al. $(1998,1999)$. To illustrate the use of their theoretical predictions, consider the following example. Sedimentary particles of size $20 \mu \mathrm{m}$ and excess density $1 \mathrm{~g} \mathrm{~cm}^{-3}$ have a settling velocity of $5 \times 10^{-2} \mathrm{~m} \mathrm{~s}^{-1}$. A suspension of these particles with concentration $5 \%$ by volume and cross-sectional area $100 \mathrm{~m}^{2}$ yield a length-scale $l_{\infty}=800 \mathrm{~m}$. In a tidal current of velocity $10 \mathrm{~cm} \mathrm{~s}^{-1}, \Lambda=0.2$ and the particle-laden current propagates upstream over a distance of $300 \mathrm{~m}$.

\section{(b) Turbidity currents}

Suspension-driven gravity flows, known as turbidity currents by geologists, are a primary mechanism by which sediment from land can be transported into the deep sea. Turbidity currents can originate from a debris flow or a gravity slide associated with sea-floor failure on the continental slope. The resulting flow can be selfsustaining and even increase in sediment load as it propagates rapidly down the continental slope through a network of submarine canyons (Pantin 1979). When the turbidity current arrives at the relatively gentle slopes of the abyssal plain, it runs 
out and deposits its sediment in the way described earlier in this paper and reviewed from a different point of view by Middleton (1993).

Sequential turbidite flows can lay down a series of beds (Pickering et al. 1989) and those composed of compacted fine material can act as traps and containers for oil. If only for this reason, detailed descriptions of many individual turbidite flows, even quite small ones, have been painstakingly constructed. The largest flows, though less numerous, may, however, be more important in large-scale descriptions of the evolution of the surface of the Earth. One of the largest turbidites to have been continuously traced on the ocean floor is found on the Hatteras Plain off the eastern coast of North America and is known as the 'Black-Shell' turbidite (Elmore et al. 1979) because of the many small black shells that litter the deposit. The turbidite lies in water $5.5 \mathrm{~km}$ deep, covers an area of at least $44 \times 10^{3} \mathrm{~km}^{2}$ and extends for more than $500 \mathrm{~km}$ along a channel flanked by abyssal hills. The problem now comes down to what a geophysicist calls an inverse problem: given the characteristics of the deposit, can one evaluate the details of the flow from which it originated? Using the observed thickness of the deposit as a function of the distance along the Hatteras Abyssal Channel, a mean fall speed $V$ of $0.08 \mathrm{~cm} \mathrm{~s}^{-1}$ (corresponding to silt-sized particles with an effective diameter of $32 \mu \mathrm{m}$ ) and the box-model results developed in $\S 3$, Dade \& Huppert (1994) showed that the deposit resulted from an initial surge $30 \mathrm{~km}$ long, $300 \mathrm{~m}$ high and ca. $200 \mathrm{~km}$ wide containing particulate matter which made up $5 \%$ by volume, and $13 \%$ by weight, of the surge.

In a subsequent paper, Dade \& Huppert (1995) analysed in a similar fashion three radially symmetric turbidites of the Hispaniola-Caicos basin in the western Atlantic Ocean.

\section{(c) Pyroclastic flows}

As the result of increased pressure in the chamber beneath a volcano, a volcanic eruption can occur during which a hot multiphase flow is ejected at speeds of hundreds of metres per second into the atmosphere. If the contribution of the heavy ash particles to the bulk density at the base of the current is too large, the eruption column collapses at a rather short height (Woods 1995) and there results what geologists call a pyroclastic flow, which is a ground-hugging ash flow driven by the bulk density difference between the flow and the atmosphere into which it intrudes. Dade \& Huppert (1996) proposed that first-order features of a pyroclastic flow could be quantitatively explained by modelling it as an isothermal, turbulently propagating, relatively low-concentration, particulate-driven gravity current. Further, they asked whether there was a reasonable solution to the inverse problem of determining the initial conditions of the flow, and especially the initial particulate concentration, given the observed distribution and extent of the resulting deposit, known as an ignimbrite by geologists.

They answered this question specifically for the eruption of Taupo on the North Island of New Zealand in AD 186, which distributed approximately $30 \mathrm{~km}^{3}$ of solid material in a roughly axisymmetric fashion about the vent up to a distance of $80 \mathrm{~km}$. From their calculations, they inferred that the total volumetric flux in the turbulent flow after collapse of the central eruption column and the entrainment that would have been associated with it was of the order of $40 \mathrm{~km}^{3} \mathrm{~s}^{-1}$ and lasted for no more than about 15 min. Further, they calculated that the initial solids' concentration in the pyroclastic flow was $0.3 \%$ by volume in a current with a thickness of around $1 \mathrm{~km}$ 
and which travelled at a typical speed of $200 \mathrm{~m} \mathrm{~s}^{-1}$. At that speed, by transferring kinetic energy into potential energy, the current could surmount any topographic barriers less than $c a .2 \mathrm{~km}$ in height. All hills within $100 \mathrm{~km}$ of Taupo are less that $500 \mathrm{~m}$ high and the deposit was draped virtually uniformly over all those hills, attesting to the energy of the flow.

It would be both fun and instructive to apply these explicit ideas to other eruptions and compare the results.

\section{(d) Other situations}

Of course there are many other areas of relevance to engineers and Earth scientists to which the concepts described above can be applied. Amongst these are the generation and maintenance of gigantic dust storms in the atmosphere. A vast wall of dust, up to $1 \mathrm{~km}$ high, can advance at speeds of $20 \mathrm{~m} \mathrm{~s}^{-1}$. Such dust storms occur regularly: in parts of Australia and the USA; in India, where they are known as 'Andhis'; and in parts of Africa, especially in the Sudan, where they are known as 'haboobs', the Arabic word for strong wind. They can cause considerable damage to animals, crops and property.

Plumes from volcanic eruptions can, as described in $\S 8$, transport large quantities of particles to heights in the atmosphere at which commercial aeroplanes commonly cruise. All aircraft are designed to operate in particle-free air and the encounter of a particle-laden plume by a plane can result in either catastrophic failure of its engines or considerable deterioration of its bodywork. Many principal air routes are over volcanic chains, but, because volcanic plumes can be advected through the atmosphere by the strong prevailing winds at height, the avoidance of the air space above a volcano does not preclude a problem. Hence accurate prediction of windblown particle-driven plumes is required in almost real time.

Finally, and possibly not the cleanest example with which to end this section, sewage companies have considerable interest in separating particles of various sizes from a flowing gravity current to end up with water as pure and particle free as possible, or at least as pure and particle free as required by local legislation. Most companies operate old systems, designed by 'suck it and see' methods. However, there is currently a move by some sewage operators to investigate their problems scientifically and quantitatively, and at least to try to incorporate some of the latest fundamental research.

Other applications of these general ideas to other problems in engineering and the Earth sciences is also likely to happen in the (near) future.

\section{Concluding remarks}

This review has painted a broad-brush picture of some of the recent work on the flow of relatively low-concentration suspensions. It has outlined the major concepts on which the models are based: quantitative descriptions of the advection and sedimentation of the particulate material; and the Froude number, or momentum balance condition, at the head. The review has discussed many special situations and given some indication of applications to engineering and the Earth sciences. A number of other phenomena could have been described but were not for lack of space. Included amongst these are the effects of rotation; varying topographic slope; high- 
concentration flows; and erosion of the bottom surface. A few remarks will now be made on each of these topics.

The Earth is a rotating system; and large-scale flows, specifically those at significantly small Rossby numbers $R o=U / \Omega l$, where $U$ and $l$ are typical velocities and lengths of the flow in a background rotation of $\Omega$, are strongly influenced by rotation. The effects of rotation are important on the shape of a spreading blob of dense fluid, even if the Rossby number is not small (Ungarish \& Huppert 1998, 1999). They showed that Coriolis effects are negligible only in the initial stages of the evolution, after which the axisymmetric flow, predicted by numerical solution of the shallow-water equations, takes up a shape which has a downward decreasing profile at the nose while the outward velocity decreases to zero in finite time. They plan to investigate these surprising, and somewhat counter-intuitive, results on the large (13 m diameter) rotating table in Grenoble during the spring of 1999. With the propagation of such blobs over the continental rise in mind, Nof (1996) investigated the paths of propagation of an isolated patch of dense inviscid fluid over a parabolic bottom. He applied the results to an analysis of the well-known record of breaks in submarine cables caused by the turbidity current resulting from the earthquake on the Grand Banks in 1929. In my opinion, much more research is still to be completed on the effects of rotation on particulate suspension flows.

Most natural boundaries are not smooth and horizontal; typical topography is considerably variable. As a first attempt to model such boundary variations, Dade et al. (1994) considered the rates of propagation of and suspension from a buoyant twodimensional cloud moving down an inclined surface (at fixed angle $\theta$ ). They found that once the cloud was initiated, the speed of its propagation decreases with the inverse square root of the distance down the slope until almost all the particulate matter has sedimented at a distance $x_{r}$, say, which they evaluated as a function of the initial conditions. A numerical programme to integrate the shallow-water equations describing the flow of a suspension over a generally varying bottom topography has been written and tested and is currently being used to evaluate general conclusions (Bonnecaze \& Huppert 1999).

It is obviously of importance to determine when the results discussed in this review, with the explicit assumption of a relatively low-concentration non-interacting suspension, are valid. To this end, Hallworth \& Huppert (1998) conducted some preliminary experiments, with each one employing a larger initial particle concentration. They found that at first, with increasing initial particle concentration, the resulting current propagated at an increased rate due to the increased buoyancy. Beyond an initial volume concentration of $c a .0 .3$, the current came to an abrupt halt at a point down the channel, depositing the bulk of its initial load as a relatively thick layer of fairly constant thickness, characterized by a pronounced steep snout. A very much thinner layer extended for some distance beyond this arrest point. Hallworth \& Huppert were not able to present a quantitative theory to explain this change in behaviour, but were pleased to be informed during the meeting that a similar transition, at about the same critical volume concentration, had been observed in shear-flow tests (Kumar \& Muir Wood 1996). High-concentration flows still need considerable further investigation, as particularly outlined in the recent review by Iverson (1997).

The erosion of a sedimentary bed, the pick up of particles, can be an important process even though it has not been explicitly mentioned in this review so far. Hogg et al. (1997) and Hogg \& Huppert (1999) determined the erosion of a bed due to 
a jet either incident upon, or directed parallel to, a loose bed of small particles. The erosion of a bed by a shear flow, in such a way as to increase the buoyancy, and hence the shear, to lead to a self-accelerating current, a process often called autosuspension, was first considered, independently, by Pantin (1979) and Parker (1982). They subsequently combined their approach (Parker et al. 1986) to derive conditions under which autosuspension occurs. Experimental confirmation of these theoretical criteria is still awaited.

I have no doubt that other interesting phenomena in this area have already been investigated, and that many more will be developed in the future. This conference, along with the resulting discussions and publications, have been greatly beneficial towards this development.

It is with much gratitude that I acknowledge the many stimulating and penetrating conversations about suspension flows from which I have benefited with my colleagues R. T. Bonnecaze, W. B. Dade, M. A. Hallworth, A. J. Hogg, J. R. Lister, R. S. J. Sparks and M. Ungarish, all of whom have been generous in sharing their thoughts with me. Parts of the paper were written while I was a short-term visitor at the Hyams Institute, and I am grateful to the Director, E. A. Sharota, for the kind hospitality given me.

\section{References}

Benjamin, T. B. 1968 Gravity currents and related phenomena. J. Fluid Mech. 31, 209-248.

Bonnecaze, R. T. \& Huppert, H. E. 1999 Particle-driven gravity currents flowing over variable topography. J. Fluid Mech. (In preparation.)

Bonnecaze, R. T., Huppert, H. E. \& Lister, J. R. 1993 Particle-driven gravity currents. J. Fluid Mech. 250, 339-369.

Bonnecaze, R. T., Hallworth, M. A., Huppert, H. E. \& Lister, J. R. 1995 Axisymmetric particledriven gravity currents. J. Fluid Mech. 294, 93-121.

Bonnecaze, R. T., Huppert, H. E. \& Lister, J. R. 1996 Patterns of sedimentation from polydispersed turbidity currents. Proc. R. Soc. Lond. A 452, 2247-2261.

Briggs, G. A. 1969 Plume rise. US Atomic Energy Commission Critical Review Series.

Bursik, M. I., Sparks, R. S. J., Gilbert, J. S. \& Carey, S. N. 1992 Sedimentation of tephra by volcanic plumes. I. Theory and its comparison with a study of the Fogo A plinean deposit, Sao Miguel (Azores). Bull. Volc. 54, 329-344.

Carey, S., Sigurdsson, H. \& Sparks, R. S. J. 1988 Experimental studies of particle-laden plumes. J. Geophys. Res. $9315314-15328$.

Dade, W. B. \& Huppert, H. E. 1994 Predicting the geometry of channelised deep-sea turbidites. Geology 22, 645-648.

Dade, W. B. \& Huppert, H. E. 1995 Runout and fine-sediment deposits of axisymmetric turbidity currents. J. Geophys. Res. 100, 18597-18609.

Dade, W. B. \& Huppert, H. E. 1996 Emplacement of the Taupo ignimbrite by a dilute turbulent flow. Nature 381, 509-512.

Dade, W. B., Lister, J. R. \& Huppert, H. E. 1994 Fine-sediment deposition from gravity surges on uniform slopes. J. Sed. Petrol., A 64, 423-432.

Dalziel, S. B. \& Linden, P. F. 1997 Application of a general purpose CFD package to RayleighTaylor instability. In Proc. of the 6th Int. Workshop on the Physics of Compressible Turbulent Mixing (ed. G. Jourdan \& L. Houas), pp. 139-144. Marseille: Université de Provence.

de Rooij, F., Linden, P. F. \& Dalziel, S. B. 1999 Saline and particle-driven interfacial intrusions. J. Fluid Mech. (Submitted.)

Einstein, H. A. 1968 Deposition of suspended particles in a gravel bed. J. Hydraul. Div. ASCE 94, 1197-1205.

Phil. Trans. R. Soc. Lond. A (1998) 
Elmore, R. D., Pilkey, O. H., Cleary, W. J. \& Curran, H. A. 1979 Black shell, turbidite, Hatteras Abyssal Plain, Western Atlantic Ocean. Geol. Soc. Am. Bull. 90, 1165-1176.

Gladstone, C., Phillips, J. C. \& Sparks, R. S. J. 1998 Experiments on bidisperse, constant-volume gravity currents: propagation and sediment deposition. Sedimentology. (In the press.)

Hallworth, M. A. \& Huppert, H. E. 1998 Abrupt transitions in high-concentration, particledriven gravity currents. Phys. Fluids 10, 1083-1087.

Hallworth, M. A., Phillips, J., Huppert, H. E. \& Sparks, R. S. J. 1993 Entrainment in turbulent gravity currents. Nature 362, 829-831.

Hallworth, M. A., Huppert, H. E., Phillips, J. \& Sparks, R. S. J. 1996 Entrainment into twodimensional and axisymmetric turbulent gravity currents. J. Fluid Mech. 308, 289-312.

Hallworth, M. A., Hogg, A. J. \& Huppert, H. E. 1998 Effects of external flow on compositional and particle gravity currents. J. Fluid Mech. 359, 109-142.

Hallworth, M. A., Hogg, A. J. \& Huppert, H. E. 1999 The influence of an ambient flow on constant flux gravity currents. J. Fluid Mech. (In preparation.)

Harris, T. 1998 Analyses of particle-driven flows in fluid mechanics. PhD thesis, University of Cambridge, UK.

Heezen, B. C. \& Ewing, M. 1952 Turbidity currents and submarine slumps and the 1929 Grand Banks earthquake. Am. J. Sci. 250, 849-873.

Hogg, A. J. \& Huppert, H. E. 1999 Models for the dispersion of particles and dense fluid in uniform flows. IAHRI. (In preparation.)

Hogg, A. J., Huppert, H. E. \& Dade, W. B. 1997 Erosion by planar turbulent jets, J. Fluid Mech. 338, 317-340.

Hogg, A. J., Ungarish, M. \& Huppert, H. E. 1999a Particle-driven gravity currents: asymptotic and box-model solutions. Euro. J. Mech. (Submitted.)

Hogg, A. J., Huppert, H. E. \& Hallworth, M. A. $1999 b$ Reversing buoyancy of particle-driven gravity currents. Phys. Fluids. (In the press.)

Hunt, J. C. R. 1991 Industrial and environmental fluid mechanics. A. Rev. Fluid Mech. 23, 1-41.

Hunt, J. C. R., Holroyd, R. J., Carruthers, D. J., Robins, A. G., Apsley, D. D., Smith, F. B. \& Thomson, D. J. 1991 Developments in modelling air pollution for regulatory uses. In Proc. 18th NATO-CCMS. Int. Tech. Mtg on Air Pollution Modelling and its Applications, Vancouver, Canada (ed. H. van Dop). New York: Plenum.

Huppert, H. E. \& Dade, W. B. 1998 Natural disasters: explosive volcanic eruptions and gigantic landslides. Theo. Comp. Fluid Dyn. 10, 201-212.

Huppert, H. E. \& Simpson, J. E. 1980 The slumping of gravity currents. J. Fluid Mech. 99, $785-799$.

Huppert, H. E., Kerr, R. C., Lister, J. R. \& Turner, J. S. 1991 Convection and particle entrainment driven by differential sedimentation, J. Fluid. Mech. 226, 349-369.

Iverson, R. M. 1997 The physics of debris flows. Rev. Geophys. 35, 245-296.

Kerr, R. C. 1991 Erosion of a stable density gradient by sediment-driven convection. Nature 353, 423-425.

Kerr, R. C. \& Lister, J. R. 1992 Further results for convection driven by differential sedimentation of particles. J. Fluid Mech. 243, 227-245.

Kumar, G. V. \& Muir Wood, D. 1996 Mechanical behaviour of mixtures of kaolin and coarse sand. In IUTAM Symp. on Mechanics of Granular and Porous Materials (ed. N. A. Fleck \& A. F. Cocks), pp. 57-68. Dordrecht: Kluwer Academic.

McCave, I. N. 1970 Deposition of fine-grained suspended sediment from tidal currents. J. Geophys. Res. 75, 4151-4159.

Martin, D. \& Nokes, R. 1988 Crystal settling in a vigorously convecting magma chamber. Nature 332, 534-536.

Martin, D. \& Nokes, R. 1989 A fluid-dynamical study of crystal settling in convecting magmas. J. Petrol. 30, 1471-1500.

Phil. Trans. R. Soc. Lond. A (1998) 
Middleton, G. V. 1993 Sediment deposition from turbidity currents. A. Rev. Earth Planet. Sci. 21, 89-114.

Morton, B. R., Taylor, G. I. \& Turner, J. S. 1956 Turbulent gravitational convection from maintained and instantaneous sources. Proc. R. Soc. Lond. A 234, 1-23.

Nisbet, E. G. \& Piper, D. J. W. 1998 Giant submarine landslides. Nature 392, 329-330.

Nof, D. 1996 Rotational turbidity flows and the 1929 Grand Banks earthquake. Deep Sea Res. 43, 1143-1163.

Pantin, H. M. 1979 Interaction between velocity and effective density in turbidity flow: phaseplane analysis, with criteria for autosuspension. Marine Geol. 31, 59-99.

Parker, G. 1982 Conditions for the ignition of catastrophically erosive turbidity currents. Marine Geol. 46, 307-327.

Parker, G., Fukushima, Y. \& Pantin, H. M. 1986 Self-accelerating turbidity currents. J. Fluid Mech. 171, 145-181.

Pickering, K. T., Hiscott, R. N. \& Hein, F. J. 1989 Deep marine environments. London: Unwin Hyman.

Quadfasel, D., Kudrass, H. \& Fische, A. 1990 Deep-water renewal by turbidity currents in the Sulu Sea. Nature 348, 320-322.

Rothwell, R. G., Thomson, J. \& Kähler, G. 1998 Low-sea-level emplacement of a very large late Pleistocene 'megaturbidite' in the western Mediterranean Sea. Nature 392, 377-380.

Rottman, J. W. \& Simpson, J. E. 1983 Gravity currents produced by instantaneous releases of a heavy fluid in a rectangular channel. J. Fluid Mech. 135, 95-110.

Simpson, J. E. 1997 Gravity currents in the environment and the laboratory. Cambridge University Press.

Simpson, J. E. \& Britter, R. E. 1980 A laboratory model of an atmospheric mesofront. Q. J. $R$. Met. Soc. 106, 485-500.

Sparks, R. S. J., Carey, S. N. \& Sigurdsson, H. 1991 Sedimentation from gravity currents generated by turbulent plumes. Sedimentology 38, 839-856.

Sparks, R. S. J., Bonnecaze, R. T., Huppert, H. E., Lister, J. R., Hallworth, M. A., Phillips, J. \& Mader, H. 1993 Sediment-laden gravity currents with reversing buoyancy. Earth Planet. Sci. Lett. 114, 243-257.

Sparks, R. S. J., Bursik, M. I., Carey, S. N., Gilbert, J. S., Glaze, L. S., Sigurdsson, H. \& Woods, A. W. 1997 Volcanic plumes. Wiley.

Turner, J. S. 1986 Turbulent entrainment: the development of the entrainment assumption and its application to geophysical flows. J. Fluid Mech. 173, 431-471.

Ungarish, M. \& Huppert, H. E. 1998 The effects of rotation on axisymmetric, particle-driven gravity currents. J. Fluid Mech. 362, 17-51.

Ungarish, M. \& Huppert, H. E. 1999 Simple models of Coriolis-influenced axisymmetric particledriven gravity currents. Int. J. Multiphase Flow. (In the press.)

von Kármán, T. 1940 The engineer grapples with nonlinear problems. Bull. Am. Math. Soc. 46, 615-683.

Whitham, G. B. 1974 Linear and nonlinear waves. Wiley.

Woods, A. W. 1995 The dynamics of explosive volcanic eruptions. Rev. Geophys. 33, 495-530.

Xu, Q. 1992 Density currents in shear flows - a two fluid model. J. Atmos. Sci. 49, 511-524.

Xu, Q. \& Moncrieff, M. W. 1994 Density current circulations in shear flows. J. Atmos. Sci. 51, $434-446$.

Phil. Trans. R. Soc. Lond. A (1998) 